social desirability bias. Further investigation of the association between $M$. genitalium infection and high-grade cervical cytology is warranted

\section{P3.117 INTRAVAGINAL PRACTICES AND HIV ACQUISITION AMONG WOMEN AT HIGH RISK FOR INFECTION IN TANZANIA AND UGANDA}

doi:10.1136/sextrans-2013-051184.0576

1,2S C Francis, $1,2 T$ T Ao, ${ }^{1,2} 2 \mathrm{D}$ Watson-Jones, ${ }^{1} \mathrm{~K}$ Baisley, ${ }^{3} \mathrm{~J}$ van de Wijgert, ${ }^{1,4} \mathrm{~J}$ Vandepitte, ${ }^{4} \mathrm{~J}$ Bukenya, ${ }^{1}, 4 \mathrm{H}$ Grosskurth, ${ }^{1} \mathrm{R} \mathrm{J}$ Hayes. 'London School of Hygiene \& Tropical Medicine, London, UK; ${ }^{2}$ Mwanza Intervention Trials Unit, National Institute for Medical Research, Mwanza, Tanzania; ${ }^{3}$ University of Liverpool, Liverpool, UK; ${ }^{4} \mathrm{MRCl}$ UVRI Uganda Research Unit on AIDS, Uganda Virus Research Institute (UVRI), Entebbe, Uganda

Background Intravaginal practises (IVP) are highly prevalent in sub-Saharan Africa and may facilitate HIV transmission. In two microbicide feasibility cohorts in North-West Tanzania and Kampala, Uganda, we describe baseline prevalence of IVP and investigate associations between IVP and HIV acquisition prospectively.

Methods We enrolled HIV-negative women who worked in bars, guesthouses and similar facilities in Tanzania and sex workers and bar workers in Uganda, and followed them quarterly for 12 and 18 months, respectively. At each visit, participants were tested for HIV and interviewed about IVP in the past 3 months. We assessed the association between IVP at each follow-up visit and HIV acquisition using Poisson regression in a combined analysis of both cohorts, controlling for potential confounders.

Results 1611 participants were enrolled (966 Tanzanians; 645 Ugandans). At enrolment, $92 \%$ of Tanzanians and $93 \%$ of Ugandans reported ever cleansing inside the vagina (Table 1); the majority who cleansed used soap/soapy water at least once (75\% of Tanzanians and $58 \%$ of Ugandans). Nearly half (49\%) of Ugandans, but only $13 \%$ of Tanzanians, reported ever inserting a substance inside the vagina. The most common substances inserted were herbs, petroleum-based jelly, detergents, aerated drinks, honey, and salt.

1472 participants contributed 71 seroconversions/1,780 pyrs. HIV incidence was 3.99/100 pyrs. Incidence was lower among women who reported cleansing in the past 3 months (aRR:0.44, 95\% CI: 0.21-0.93). HIV incidence was similar in women cleansing with soap and those not cleansing/cleansing with water only.

Abstract P3.117 Table 1 Reported IVP at enrolment among women at increased risk for HIV in Tanzania and Uganda

\begin{tabular}{|c|c|c|}
\hline Type of IVP used in the last 3 months & $\begin{array}{l}\text { Tanzania } \\
(\mathrm{N}=966)\end{array}$ & $\begin{array}{l}\text { Uganda } \\
(N=645)\end{array}$ \\
\hline Intravaginal Cleansing & $891(91.9 \%)$ & $601(93.2 \%)$ \\
\hline \multicolumn{3}{|c|}{ Of those who cleansed, substances ever used } \\
\hline Water only & $352(39.5 \%)$ & $250(41.6 \%)$ \\
\hline Water and Soap & $664(74.5 \%)$ & $351(58.2 \%)$ \\
\hline Other & $1(0.1 \%)$ & $2(0.3 \%)$ \\
\hline Intravaginal Insertion & $122(12.6 \%)$ & $504(49.0 \%)$ \\
\hline \multicolumn{3}{|l|}{ Of those who inserted, substances ever used } \\
\hline Herbs or other traditional substance & $55(45.1 \%)$ & $139(44.1 \%)$ \\
\hline Washing powder or detergent & $27(22.1 \%)$ & $63(20.0 \%)$ \\
\hline $\begin{array}{l}\text { Petroleum-based jelly or lotion } \\
\text { (e.g Vaseline) }\end{array}$ & $40(32.8 \%)$ & $99(31.4 \%)$ \\
\hline Lemon & $15(12.3 \%)$ & $7(2.2 \%)$ \\
\hline Aerated drinks (e.g. Coca Cola) & $0(0.0 \%)$ & $113(35.9 \%)$ \\
\hline Honey & $4(3.3 \%)$ & $64(20.3 \%)$ \\
\hline Salt & $1(0.8 \%)$ & $61(19.4 \%)$ \\
\hline Other & $19(15.6 \%)$ & $1(0.3 \%)$ \\
\hline
\end{tabular}

Inserting detergent (aRR:3.05, 95\% CI: 1.30-7.18) or petroleumbased jelly (aRR:2.52, 95\% CI: 1.08-5.89) were associated with HIV incidence.

Conclusions Intravaginal cleansing was highly prevalent in both cohorts; however, insertion was more common among Ugandans. Cleansing was not a predictor of HIV in this study, and may be protective; however, some substances used for insertion may be harmful. These rarer and more harmful types of IVP warrant further investigation.

\section{P3.118 HIGH RATES OF CHLAMYDIA AND GONORRHEA INFECTION IN ANAL AND PHARYNGEAL SITES IN MEN WHO HAVE SEX WITH MEN (MSM) AND TRANSGENDER WOMEN (TW) IN LIMA, PERU}

doi:10.1136/sextrans-2013-051184.0577

'S R Leon, ${ }^{2} \mathrm{E}$ R Segura, ${ }^{2} \mathrm{~J} \mathrm{D}$ Klausner, ${ }^{2 K} \mathrm{~K}$ Konda, ${ }^{1} \mathrm{~J}$ A Flores, ${ }^{1} \mathrm{~A}$ Silva-Santisteban, ${ }^{2} \mathrm{~J}$ T Galea, ${ }^{2} \mathrm{~T} J$ Coates, ' $\mathrm{C}$ F Caceres. 'Universidad Peruana Cayetano Heredia, Lima, Peru; 2University of California, Los Angeles, Los Angeles, CA, United States

Background The prevalence of Chlamydia trachomatis and Neisseria gonorrhoeae infections men who have sex with men (MSM) and transgender women (TW) in low and middle income countries is poorly understood. As part of a large intervention trial to reduce HIV and sexually transmitted infection (STI) incidence among MSM/TW in Lima, Peru, we analysed the baseline pre-intervention prevalences of anal and pharyngeal chlamydial and gonococcal infections as well as risky sexual behaviours.

Methods We conducted a cross sectional analysis of 718 MSM/ TW enrolled in the Comunidades Positivas and Enhanced Partner Therapy Trial in 2008. Chlamydia trachomatis and Neisseria gonorrhoeae were tested using APTIMA ${ }^{\circledR}$ Combo2 in pharyngeal swabs and self-collected anal swabs. Based on very low rates found in a pilot study, urethral testing was not undertaken. Behavioral surveys were also conducted using Computer-assisted self interviews.

Results In anorectum and oropharynx, the prevalence of Chlamydia trachomatis infection was 19\% (95\% CI: $16.1 \%-22.0 \%$ ) and $4.8 \%$ (95\% CI: $3.3 \%-6.6 \%$ ) respectively, while the prevalence of Neisseria gonorrhoeae infection was $9.6 \%$ (95\% CI: $7.5 \%-11.9 \%)$ and $6.5 \%$ (95\% CI: $4.8 \%-8.5 \%$ ), respectively for the same sites. $67 \%$ of participants reported receptive anal sex, and $62 \%$ reported any unprotected intercourse.

Conclusion We found a high prevalence of rectal and pharyngeal bacterial STIs along with high frequency of unprotected anal intercourse among MSM/TW in urban Lima. Studies to demonstrate the clinical and public health benefits of routine screening and treatment of anal and pharyngeal STIs in MSM/TW should be considered.

\section{P3.119 SEROLOGICAL TRENDS OF HIV AND SYPHILIS AMONG MEN WHO HAVE SEX WITH MEN (2004 TO 2011) IN MUMBAI, INDIA}

doi:10.1136/sextrans-2013-051184.0578

'M S Setia, ${ }^{2 R}$ Thorat, ${ }^{2} \mathrm{~V}$ Anand, ${ }^{2} \mathrm{~A}$ Row-Kavi. 'Consultant Dermatologist \& Epidemiologist, Mumbai, India; ${ }^{2}$ The Humsafar Trust, Mumbai, India

Background Men who have sex with men (MSM) have been the focus of intensive HIV public health programmes in India since 2000. We present certain demographic, and HIV and syphilis trends among MSM over an eight year period (2004 to 2011) in Mumbai, India.

Methods A total of 11,205 MSM (>= 18 years) were analysed. We calculated the proportion of HIV and syphilis positivity in them. We used chi square for trend to compare the proportions and logistic regression models to estimate the association between demographics and time, and HIV positivity. 